\title{
Development and role of retinal glia in regeneration of ganglion cells following retinal injury
}

\author{
Robert E MacLaren
}

\begin{abstract}
Aims/background-Recent observations have shown that the glial scar resulting from a surgical lesion of the immature retina differs from elsewhere in the central nervous system, in that it permits the through growth and reconnection of regenerating axons. This study in the opossum examines in detail the development and reaction to injury of retinal glia at different developmental stages, and specifically examines the distribution of the gliosis related inhibitory molecule, chondroitin sulphate proteoglycan (CSPG), making comparisons with a control site of gliosis in the cerebral cortex.

Methods-A linear slit was cut into the retina or cortex with a fine tungsten probe. After a variable time delay, immunocytochemistry of the resulting gliosis was employed to detect astrocytes with glial fibrillary acidic protein (GFAP), Müller cells with vimentin, and CSPG with CS-56 antibodies. GFAP was also used at different ages to examine the normal development of astrocytes in the retina of this species.

Results-Astrocytes entered the retina 12 days after birth (P12), closely associated with blood vessels in the nerve fibre layer. In experiments at all ages studied, cellular continuity was re-established across the lesioned retina, which did not result in a significant astrocyte proliferation or CSPG expression. In contrast, cortical injury led to the development of a cystic cavity surrounded by astrocytes and CSPG. Müller cells expressed GFAP but not CSPG in the lesioned retina.

Conclusion-Successful regrowth of ganglion cells through a retinal lesion may be partly the result of the scarcity of astrocytes in the retina, which results in minimal gliosis, or of their apparent inability to express inhibitory molecules.

(Br F Ophthalmol 1996; 80: 458-464)
\end{abstract}

The failure of axons to regenerate in the central nervous system (CNS) of mammals is multifactorial. Firstly, the lesioned neurons need to be provided with appropriate trophic factors in order to prevent programmed cell death and to facilitate re-extension of an axon. ${ }^{1-3}$ Secondly, the re-extending axon must be allowed to pass unimpeded through the CNS tissue; the myelin of oligodendrocytes is normally inhibitory to axonal growth. ${ }^{4-6}$ Thirdly, the re-extending axon must negotiate an inhibitory gliotic barrier formed by reactive astrocytes around the lesion site. ${ }^{7-9}$ Finally, one must consider re-navigation to appropriate targets and reformation of functional neural connections. ${ }^{10}$

In the mammalian visual system, success has been achieved in overcoming all of these factors. Specific molecules have been identified that can promote the survival of axotomised ganglion cells: brain derived neurotrophic factor ${ }^{3}$; inhibitors of protease and microgliad; and, as yet undetermined, factors present in peripheral nerves. ${ }^{11}$ To connect to central targets, ganglion cell axons also need to traverse the thickly myelinated optic nerve, but this too can be overcome, either by the antibody mediated blocking of myelin associated inhibitory factors, ${ }^{12}$ or by simply bypassing the optic nerve altogether with a surgically inserted peripheral nerve graft. ${ }^{13} 14$ By connecting the other end of the graft to the colliculus, these latter experiments have also demonstrated the ability for regenerating ganglion cells to reform functional connections ${ }^{15}$ and to restore the light reflex. ${ }^{16}$

In contrast with peripheral nerve grafting, our experiments focus on the possibility of regeneration through the existing visual pathways. In lower vertebrates, ganglion cells can regenerate back along a cut optic nerve and reform topographic maps in the tectum, leading to a return of vision. ${ }^{17}$ It is highly likely, therefore, that successful return of vision in mammals would also require correct re-establishment of topographic maps in central targets, which would be more likely if regeneration could simply repeat the sequence of events that normally occur during development. ${ }^{18}$ Formerly, we described the capacity for retinal ganglion cells to regrow through a surgical lesion in the developing mammalian retina (opossum) and re-navigate appropriately at the optic chiasm. ${ }^{12} 20$ Of particular interest in those experiments was the observation that regrowing ganglion cells passed directly through the gliotic scar in the retina; a phenomenon not observed elsewhere in the CNS, where gliotic scars usually form a barrier impenetrable to regrowing axons. ${ }^{21} 22$

Further investigation into the structure of glia in the retina and the gliotic reaction to a surgical insult may therefore help in our understanding of mechanisms important for successful regeneration of axotomised ganglion cells. The aims of the experiments described in this
Anatomy, University of Oxford, South Parks Road, Oxford OX1 3QX

Accepted for publication 19 January 1996 
paper are therefore threefold. Firstly, to examine the normal and comparative histology of retinal glial cells in the adult opossum. Secondly, to observe the development of astrocytes in the retina of this species, and to correlate this with the known critical postnatal period (up to P12) in which regrowth of ganglion cells through a retinal lesion is known to occur. Finally, to compare the gliotic reaction of the retina to another CNS site (cortex), looking specifically for immunoreactivity for chondroitin-6-sulphate proteoglycan (CSPG), a molecule expressed by reactive astrocytes and which is known to be inhibitory to axonal growth. ${ }^{8}$

\section{Materials and methods}

The opossum Monodelphis domestica was used for this study. The advantage of using metatherian (marsupial) mammals lies in their predominantly postnatal CNS development. Whereas in rodents, ganglion cell genesis and central retinal connections are virtually complete at birth, ${ }^{23} 24$ in the opossum these events occur almost entirely postnatally. ${ }^{25} 26$ Thus, the investigation and experimental manipulation of factors common to the developing visual system of all mammals can be made in the postnatal opossum without the need for intrauterine surgery. As a rough guide, $\mathrm{CNS}$ development at 2 weeks old in this species is comparable with a 1 day old mouse or rat. ${ }^{27}$

At various postnatal ages Monodelphis pups were detached from the maternal teats and killed by anaesthesia with ether. The brain, base of skull, orbit, and overlying cranium were dissected free from the mandible and immediately frozen in OCT (Sigma, UK) at $-20^{\circ} \mathrm{C}$. Cryostat sections were then taken at $12 \mu \mathrm{m}$ through the optic nerve and optic nerve head and collected onto $5 \%$ gelatinised slides. After a period of 15 minutes of air drying, the sections were fixed with $4 \%$ paraformaldehyde for a further 20 minutes, washed three times in pH 7.4 phosphate buffered saline (PBS), and incubated overnight at $4^{\circ} \mathrm{C}$ with primary antibodies as follows:

GFAP (polyclonal rabbit IgG, Dako, UK or monoclonal GA-5 mouse IgG, Sigma, UK) diluted 1:500 in PBS with $1 \%$ bovine serum albumin (BSA) and 4\% normal goat serum (NGS).

Vimentin (monoclonal mouse IgG, Dako) diluted 1:500 in PBS with 1\% BSA and 4\% NGS.

CSPG (monoclonal CS-56 mouse IgM, Sigma) diluted $1: 100$ in PBS with $1 \%$ BSA and 4\% NGS.

Myelin basic protein (MBP: monoclonal mouse IgG, Böhringer-Mannheim, UK) diluted $1: 200$ in PBS with $1 \%$ BSA, 4\% NGS, and $1 \%$ Triton-X100 (Sigma).

Secondary antibodies used were fluorescein conjugated goat anti-rabbit IgG, or rhodamine conjugated goat anti-mouse IgG or IgM, depending on the immunoglobulin subclass of the primary antibody. These were diluted 1:200 in PBS with 4\% NGS and added to the sections for 1 hour at room temperature after washing off the primary solutions. In the double labelling experiments, both primary antibodies were added together in the same solution, but the secondaries were added sequentially: goat anti-rabbit for 1 hour, a 30 minute block with $4 \%$ NGS, then goat antimouse for 1 hour. All secondaries were washed off with three rinses of PBS and the slides coverslipped with Aquamount (BDH, UK) mounting medium.

In selected cases, the penultimate wash contained a $0.001 \%$ solution of $4^{\prime}, 6$-diamidino-2phenylindole (DAPI: Sigma), a DNA groove binding protein that gives a blue fluorescence to all cell nuclei. Specimens were photographed with appropriate filters under a Leica fluorescence microscope with single, double, or triple exposures. Control sections (with primary or secondaries omitted) confirmed the specificity of all the immunolabelling described.

Five adult animals were in the experimental group undergoing either a retinal $(n=5)$ or cortical $(n=2)$ lesion; three neonates underwent a retinal lesion only (P7, P10, and P15). Sterile surgery was performed under an inhaled anaesthetic (halothane 5\%) in oxygen, delivered via a face mask in an open circuit. A fine tungsten probe was employed to make surgical lesions in the temporal retina using a method previously described in detail. ${ }^{20}$ Briefly, this involved passing the sharp tungsten probe through the lateral part of the globe behind and parallel to the ora serrata. With the probe held in place as a cutting edge internally, a sharpened pair of forceps was then scored along the outside of the globe, giving the two instruments a scissor-like action. This resulted in a slit cut in the retina from inside to out, minimising damage to the sclera and lens. For cortical lesions, a small burr hole was made over the parietal bone (lateral to the superior sagittal sinus) and a similar probe inserted to a depth of $5 \mathrm{~mm}$ into and perpendicular to the underlying parietal cortex. This probe was then swept through an arc laterally to an angle of about 45 degrees and then slowly withdrawn, thus lesioning the underlying cortical tissue in a similar fashion to the retina. The skin was closed with $6 / 0$ silk and the animals survived for a variable period of 3-90 days (mostly 7-8 days), before being killed with an intraperitoneal injection of barbiturate. The eyes and lesioned areas of cortex were marked for orientation and removed from the bony skull. Immunocytochemistry followed the methods described above, with sections cut perpendicular to the linear lesions.

\section{Results}

DEVELOPMENT OF RETINAL ASTROCYTES

The pattern of GFAP reactivity was identical with both monoclonal and polyclonal antibodies. From the day of birth (P0) to P8, no GFAP reactivity could be detected in the optic nerves or retina (Fig 1A). In one specimen, very low levels of GFAP reactivity could be 
Figure 1 The development of glial fibrillary acidic protein (GFAP)

immunoreactivity in the retina. No GFAP is seen at PO (A: ONH=optic nerve head). By P10, light GFAP staining is seen in the optic nerve head only (B: arrows), spreading to the inner layers of the retina at P12 (C: arrows) and having an adult pattern by P15 (D: arrows) In the adult, GFAP is distributed throughout the nerve fibre layer $(E) . G C L=$ ganglion cell layer, INL= inner

nuclear layer, $O N L=$ outer nuclear layer. Myelinating oligodendrocytes (MBP:

orange) are separated from the retina by densely

labelled GFAP at the optic nerve head $(F)$.

Morphology of labelled cells confirms the specificity of $G F A P$ for astrocytes ( $G$ : green) and vimentin (VIM) for Müller cells (G: red). Nuclei of astrocytes are co-located with nuclei of ganglion cell (G: blue). En face section through the nerve fibre layer $(H)$ reveals the regular spacing of radially orientated Miuller cells (dots) and a close association of astrocytes (green) to a retinal blood vessel (dark band). Scale bars: $A, B, C, D$, and $H=25 \mu \mathrm{m} ; E$ and $F=50$ $\mu \mathrm{m} ; H=10 \mu \mathrm{m}$.
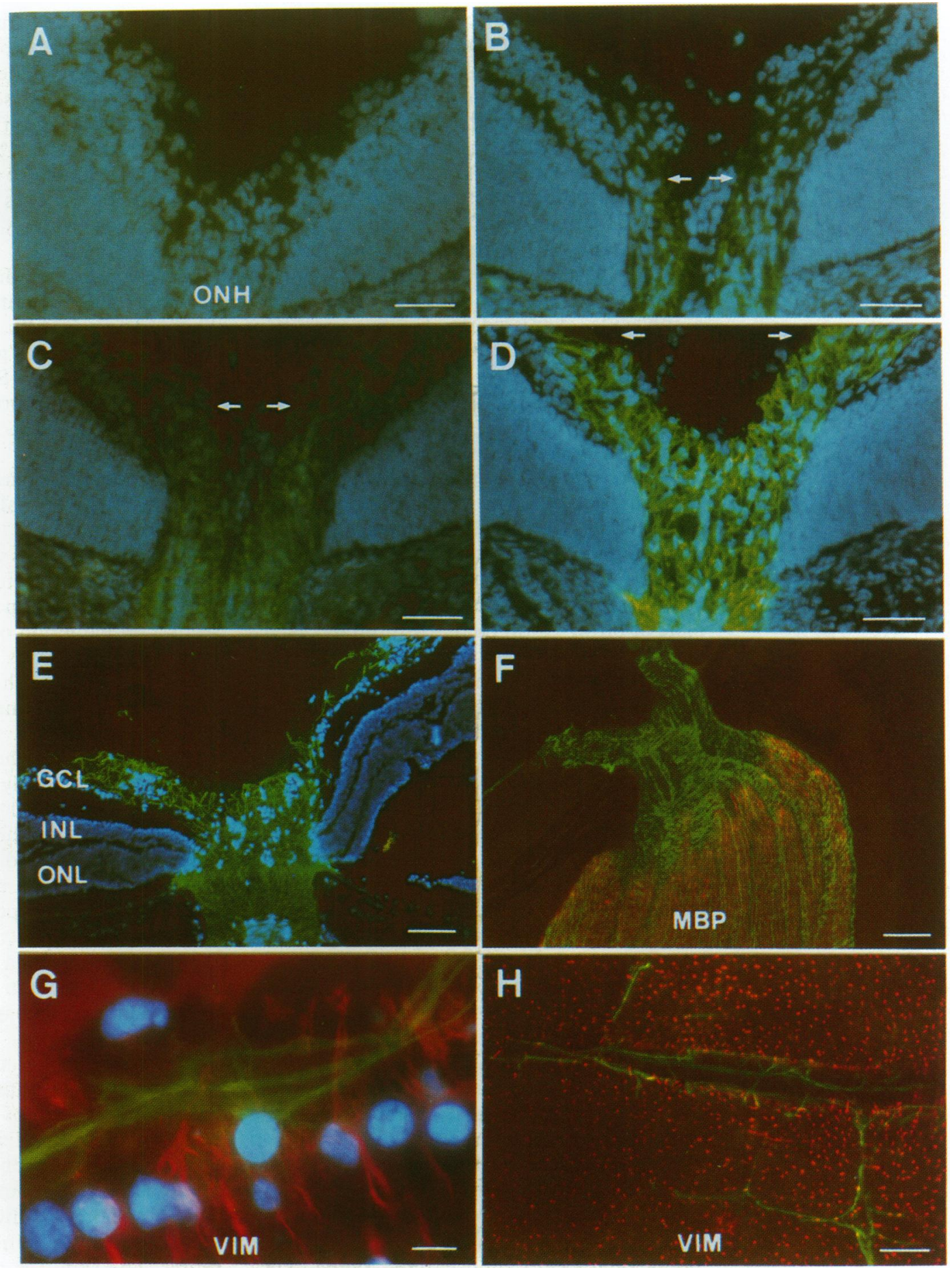

detected in the optic canal at P1 (not shown). This was identified as a part of the ophthalmic division of the trigeminal nerve, which interestingly shares the same foramen as the optic nerve in marsupials. ${ }^{28}$ From P8 to P10, GFAP labelling increased diffusely throughout the nerve and was detectable at the optic nerve head at P10 (Fig 1B, arrows). By P12, GFAP reactivity had entered the retina to occupy the nerve fibre layer in the region of the optic nerve head (Fig 1C, arrows) and by P15, had spread out radially along the nerve fibre layer to reach the retinal periphery (Fig 1D, arrows). At P15 the intensity and distribution of GFAP reactivity was not dissimilar to the adult pattern; any differences thereafter were related to a general increase in size and differentiation of retinal layers (Fig 1E). The apparent 'invasion' of the retina by motile GFAP labelled cells was in contrast with the optic nerve where GFAP labelling increased uniformly throughout the length of the nerve, and was more in keeping with a maturation of fixed cells in situ.

DISTRIBUTION OF GLIAL CELLS IN THE ADULT RETINA

The distribution of GFAP in the normal retina of the adult opossum, together with the morphology of individual GFAP labelled cells, was similar to the known distribution of astrocytes in other species. ${ }^{29-32}$ There was no difference in the immunolabelling seen with the monoclonal GFAP (GA-5 clone) or polyclonal GFAP antibody, on either independently or double labelled specimens.

Astrocytes occupied the nerve fibre layer and labelling was thus most dense around the 
Figure 2 Glial response to lesions in the retina and cortex; dotted line with arrow indicates direction and site of cut. Astrocytic response (to glial fibrillary acidic protein, $G F A P$ ) is present throughout the inner layers of the retina, but is not located around the lesion itself $(A)$. In contrast, astrocytes can be seen to 'wall off' a cavitating cortical lesion (B). Chondroitin sulphate (CSPG) is seen distributed around a lesion of the cortex (D: arrowheads) but not in the retina: here it is found only in lens debris (C: arrowhead). Triple labelling with DAPI, CSPG, and GFAP (E and $F$ ) shows a restoration of cellular continuity only across a retinal lesion ( $E$ : blue nuclei) and a colocalisation of CSPG and GFAP only around $a$ cortical lesion (F). GFAP is seen predominantly on Mïller cells in lesioned retina (E: arrows). Nonspecific labelling detects epithelial-like cells only in lesioned cortex (F: arrows). GFAP expression is seen on Miuller cells away from the lesion site, but astrocytes can still be identified

(G: arrows). For

comparison, a control retina (H) shows the normal specificity of Müller cells for vimentin only (arrows) and the normal morphology of a GFAP positive retinal astrocyte. $G C L=$ ganglion cell layer, INL=inner nuclear layer, $O N L=$ outer nuclear layer. Scale bars: $A, B, C, D$, and $G=50$ $\mu m ; E, F$, and $H=25 \mu \mathrm{m}$.
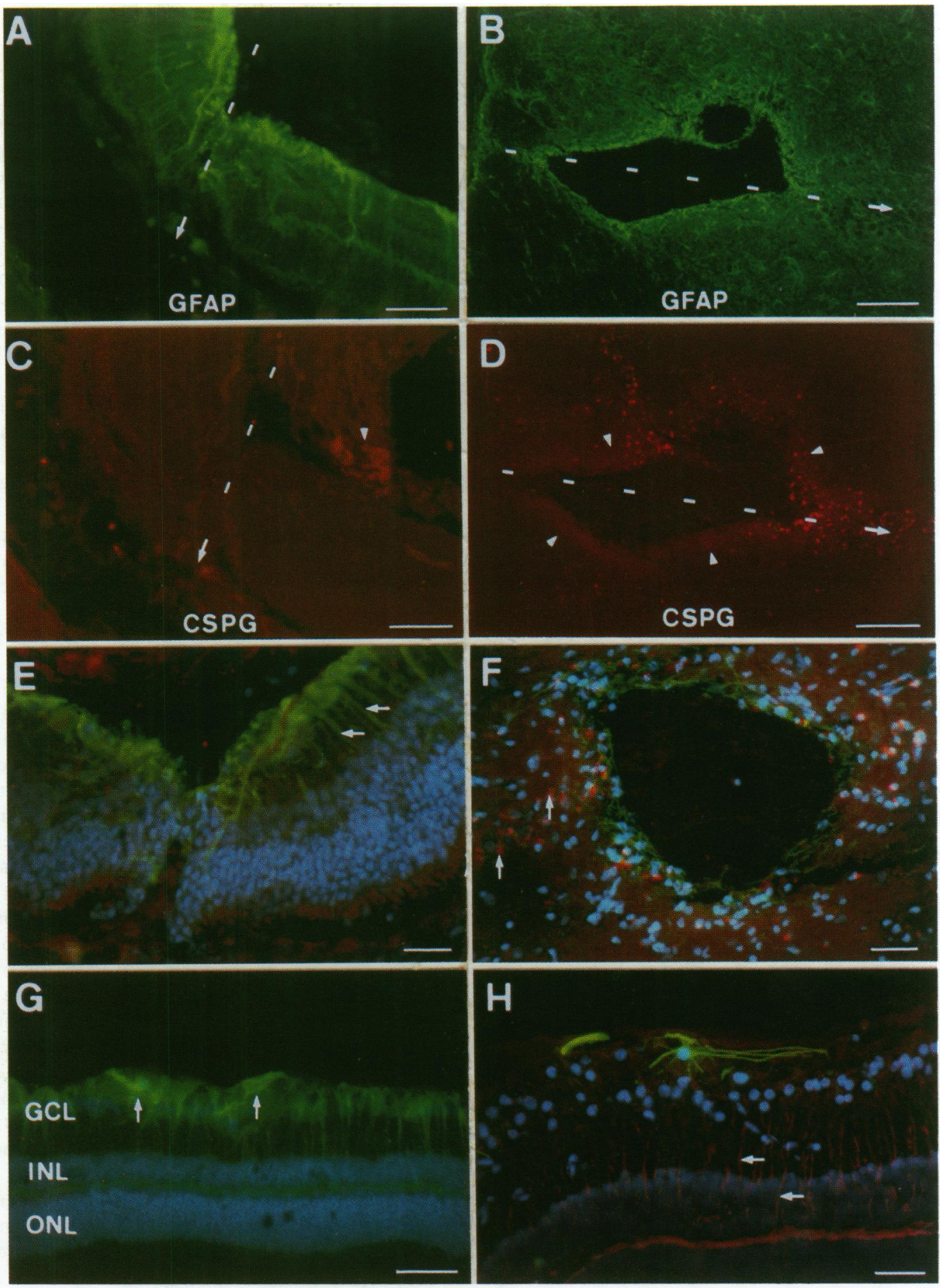

optic nerve head (Fig 1E). Just behind the optic nerve head the GFAP staining became slightly lighter at the junction with the myelinated part of the optic nerve. Here MBP labelled oligodendrocytes interdigitated with GFAP labelled astrocytes (Fig 1F).

The addition of an antibody to vimentin labelled the other glial cell type in the retina the Müller cell. ${ }^{33}{ }^{34}$ These cells were orientated radially and perpendicular to the astrocytes, and exhibited no identifiable GFAP reactivity (Fig 1G). Towards the retinal periphery, single astrocytes could be identified (Figs IG and $2 \mathrm{H})$. Although co-located with the nuclei of ganglion cells, the nuclei of astrocytes differed by their heavy DAPI labelling, reflecting the strong chromatin staining normally observed in glial cells. Peripheral astrocytes were invariably seen associated with blood vessels. Small foot-like processes connected the astrocytes to the walls of the vessels and followed these structures into the deeper retinal layers (Fig $1 \mathrm{H})$, in keeping with the role of maintaining the blood-ocular barrier. ${ }^{35}$

GLIAL RESPONSE TO INIURY IN THE RETINA

Typically the injured retina at all ages studied showed an increase in GFAP reactivity, owing to fresh expression by 'reactive' Müller cells rather than a proliferation of astrocytes around the lesion site. This increase was detected 3 days after injury and persisted until at least 3 months; a typical example is shown in Figure 2A. In contrast, a cortical lesion led to a marked proliferation of astrocytes, resulting in a dense ring of GFAP reactivity around the lesion site (Fig 2B). 
The distribution of CSPG (monoclonal CS56 antibody raised against chondroitin-6sulphate) mirrored the increase in GFAP expression in the cortex but not in the retina (Fig 2C and D). No CSPG reactivity was seen around the lesion site in the retina, or among the GFAP labelled Müller cells, whereas a clear halo could clearly be identified around cortical lesions (Fig 2D, arrowheads). Epithelial-like cells were also labelled around the lesion site in the cortex (Fig 2F, arrows). The labelling was non-specific, being present on cortex control sections without primary antibody, but is worth mentioning, since the cells have the appearance typical of macrophages and were not seen in the retina. Standard secondary antibodies are not adsorbed onto opossum sera, and since one might expect macrophages to be full of immunoglobulin debris, chance cross reactions with a non-specific immunoglobulin epitope is not surprising. Macrophage specific antibodies, however, would be required to definitively confirm the absence of these cells in the lesioned retina. Interestingly, cellular continuity appeared to be re-established at the lesion site in the retina, whereas the lesion site in the cortex remained open and acellular (Fig 2E and 2F, DAPI/blue cell nuclei).

The transition to GFAP reactivity affected Müller cells throughout the retina and not just those around the lesion site (vimentin reactivity was unaffected). Astrocytes could be differentiated from these 'reactive' Müller cells by their position, shape, and a slightly heavier GFAP staining (Fig 2G, arrows). Where identified, astrocytes were relatively unchanged by the retinal lesion in terms of morphology and number. The opposite eye appeared unaffected by the lesion and contained vimentin positive Müller cells only (Fig 2H).

\section{Discussion}

We have observed a development of GFAP reactivity in the retina of the opossum at P10-P15. This pattern is consistent with an invasion of astrocytes through the optic nerve head, which has previously been noted in the rat. ${ }^{31}$ The microscopic structure and location of mature retinal astrocytes is in keeping with a function associated with retinal blood vessels. ${ }^{35}$ The glial response to injury differs markedly between retina and cortex. In the cortex, the reaction is similar to that seen elsewhere in the CNS, with a proliferation of astrocytes (gliosis) and secretion of a molecule inhibitory to axonal growth (CSPG) seen around the lesion site. 83637 In the retina, however, the glial response is seen almost entirely within the Müller cell population, which becomes 'activated' with a switch to GFAP expression. No proliferation of astrocytes or CSPG localisation is seen following retinal injury.

DEVELOPMENT AND FUNCTION OF RETINAL GLIA

Two types of glial cell have been described in the mammalian retina - Müller cells and astrocytes. The former are believed to differentiate from the neuroepithelium of the primitive retina ${ }^{38}$ and are usually immunoreactive for the intermediate filament protein, vimentin. ${ }^{34}$ In contrast, the latter are immunoreactive for a different intermediate filament protein (GFAP) and are believed to migrate into the retina from glial precursors in the optic nerve. This migratory theory of retinal astrocytes is supported by both immunohistochemical ${ }^{3132}$ and retroviral gene transfer studies. ${ }^{39}$ Unlike Müller cells, retinal astrocytes are found distributed in contact with retinal blood vessels 3140 and are absent in species with avascular retinas. ${ }^{38}$ These observations may reflect a role for the retinal astrocyte as the principal glial cell maintaining the blood-ocular barrier. ${ }^{35}$ In this study, GFAP reactivity is also seen to spread from the optic nerve into the inner layers of the retina, and GFAP positive processes with endfeet are seen in contact with blood vessels in en face sections through the nerve fibre layer of the retina. These results are therefore evidence for a similar role for retinal astrocytes in the opossum.

In the rabbit, oligodendrocytes myelinate nerve fibres in the retina. ${ }^{29}$ These glial cells are inhibitory to axonal growth and regeneration, ${ }^{41}$ but this study has demonstrated no evidence of myelin proteins in the retina of the opossum; MBP immunoreactivity was seen only in the optic nerve. A previous developmental study in this species demonstrated a rapid progression of MBP and other myelin proteins along the optic nerve from the chiasm, meeting the eye at P34. ${ }^{42}$ Here we confirm that further progression of myelin into the retina is halted at the lamina cribrosa, where labelled areas of GFAP abruptly interdigitate with MBP (Fig 1F). Previous reports have argued for the existence of a highly motile progenitor cell to the oligodendrocyte, which migrates into regions of future myelination in the CNS. ${ }^{43} 44$ The absence of myelin in the retina of species possessing a lamina cribrosa has led to the belief that dense glial elements in this region obstruct the migration of oligodendrocyte progenitors into the retina. ${ }^{454}$ In this study we have seen that GFAP appears considerably earlier than MBP at the lamina cribrosa. Since the motile oligodendrocyte precursors would be present in the nerve some time before MBP is expressed by fully differentiated oligodendrocytes, this early differentiation of astrocytes may be a necessity to prevent migration of oligodendrocyte progenitors into the retina of the opossum.

\section{ROLE OF GLIA IN REPAIR AND REGENERATION} One of the factors preventing successful axonal regeneration is the development of a dense glial scar after CNS injury. The glial scar consists predominantly of 'reactive' astrocytes meshed together in attempt to wall off the injured area, but also results in a physical obstruction to the passage and reconnection of lesioned neurons. ${ }^{47-49}$ This 'gliosis' also contains molecules that are inhibitory to axonal 
growth. ${ }^{8}$ A previous study in Monodelphis has highlighted differences in the glial response following injury in the retina. ${ }^{20}$ In that study, immature axons were able to regrow directly through a retinal lesion; elsewhere in the CNS, similar experiments have shown immature axons can only regrow around the site of injury. 215051 In the adult CNS, alteration of inhibitory and trophic factors has allowed limited regeneration, but regrowing axons still require intact unlesioned tissue in which to grow. ${ }^{22}$ In contrast, when embryonic tissue is transplanted into the CNS, axons can regrow directly across the resulting glial interface, suggesting the gliotic response from immature astrocytes may be less inhibitory ${ }^{52-54}$; a fact also supported by in vitro studies. ${ }^{75}$

The results presented here appear to correlate well with a previous observation. ${ }^{20}$ In that study, the end of a critical period in which axons could regrow through a retinal lesion was P12, seen here to be the same stage at which astrocytes start to appear in the retina. One might therefore conclude that the development of retinal astrocytes (and therefore resulting gliosis) is the major factor preventing further regeneration. An alternative hypothesis, however, is that the timing of these two events may simply be a coincidence, since this study has also shown that the inhibitory gliotic response of retinal astrocytes is virtually nonexistent when compared with the cortex.

Firstly, the patterns of GFAP expression are different; localised around the edges of a cortical lesion, but distributed more diffusely throughout the whole of the injured retina. This suggests the retinal astrocytes are not 'walling off' the damaged area of retina in the manner usually seen in post-injury gliosis elsewhere. 4856 Secondly, a chondroitin sulphate inhibitory molecule (CSPG) normally associated with astrocytic gliosis ${ }^{857}$ was seen in the lesioned cortex, but not in the retina. Perhaps this is not surprising, considering the absence of a significant astrocytic reaction in the retina, but it may also indicate that reactive Müller cells do not secrete this inhibitory molecule. Interestingly, during embryogenesis of the rat retina, CSPG is expressed peripherally by primitive retinal glia, suggesting a developmental role in repelling ganglion cell axons back towards the optic disc. ${ }^{58}$ Thirdly, in the retina there is continuity across the site of the lesion, whereas a clear cavity exists in the lesioned cortex. This observation may be the result of intrinsic physical differences in the tensions of the tissues in these two sites, or may be secondary to the different degrees of gliosis described above. Clearly, re-establishment of axonal continuity across a CNS lesion is far more likely if the wound edges are in close apposition. The importance of tissue continuity for successful CNS regeneration is also corroborated by a previous observation of plasticity in the developing spinal cord of the opossum. In that study, the end of the critical period coincided, not with the initial formation of a glial scar, but with the stage at which cystic cavities developed around the lesion site. ${ }^{59}$
Finally, the presence of Müller cells is unique to the retina, and their transition to GFAP immunoreactivity after lesioning remains unexplained. The novel appearance of GFAP encoding mRNA in Müller cells following retinal injury suggests this is an active process rather than an immunological artefact. ${ }^{60}$ Müller cells also express GFAP in a variety of other retinal disorders; for instance, photoreceptor degeneration, ${ }^{61}$ optic nerve lesion, ${ }^{62}$ and retinal detachment. ${ }^{63}$ This suggests the reaction is not a direct result of piercing the globe or severing axons, as in our study, but a more general reaction to retinal injury. Furthermore, the widespread distribution of reactive Müller cells indicates that the signal for GFAP transcription exists throughout the eye, and is not specifically localised to the lesion site or to degenerating axons.

\section{CONCLUSIONS}

The results of this study have therefore highlighted many differences in the glial response of the injured retina to elsewhere in the CNS. Unique cellular, molecular, and physical factors result in a reduced retinal gliosis, which is far more favourable for retinal axon regrowth. These factors may partly explain why ganglion cells regenerate so successfully into retinal grafts, and should warn us against assuming that the general rules for CNS regeneration also apply to the visual system.

I am very grateful to the project supervisor, Dr Jeremy Taylor, for his support and helpful comments on the manuscript. This research was supported by the Medical Research Council research was supported by the
clinical training fellowship scheme.

1 Thanos S, Mey J, Wild M. Treatment of the adult retina with microglia-suppressing factors retards axotomyinduced neuronal degradation and enhances axonal regeneration in vivo and in vitro. $\mathcal{f}$ Neurosci 1993; 13: regenera

2 Yan Q, Elliot J, Snider WD. Brain-derived neurotrophic factor rescues spinal motor neurons from axotomyinduced cell death. Nature 1992; 360: 753-5.

3 Wiebel D, Kreutzberg GW, Schwab ME. Brain-derived neurotrophic factor (BDNF) prevents lesion-induced axonal die-back in young rat optic nerve. Brain Res 1995; 679: 249-54.

4 Caroni P, Schwab ME. Two membrane protein fractions from rat central myelin with inhibitory properties for from rat central myelin with inhibitory properties for 106: 1281-8.

5 Fawcett JW, Rokos J, Bakst I. Oligodendrocytes repel axons and cause growth cone collapse. $\mathcal{F}$ Cell Sci 1989; 92: 93-100.

6 Mukhopadhyay G, Doherty P, Walsh FS, Crocker PR, Filbin MT. A novel role for myelin-associated glycoprotein as an inhibitor of axonal regeneration. Neuron 1994; 13: 757-67.

7 Rudge JS, Silver J. Inhibition of neurite outgrowth on astroglial scars in vitro. F Neurosci 1990; 10: 3594-603.

8 McKeon RJ, Schreiber RC, Rudge JS, Silver J. Reduction of neurite outgrowth in a model of glial scarring following CNS injury is correlated with the expression of inhibitory molecules on reactive astrocytes. $\mathcal{F}$ Neurosci 1991; 11: 3398-411.

9 Fawcett JW, Housden E, Smith-Thomas L, Meyer RL. The growth of axons in three-dimensional astrocyte cultures. Dev Biol 1989; 135: 449-58.

10 Holder N, Clarke JDW. Is there a correlation between continuous neurogenesis and directed axon regeneration in the vertebrate nervous system? TINS 1988; 11: 94-9.

11 Cho EYP, So KF. Characterization of the sprouting response of axon-like processes from retinal ganglion cells after axotomy in adult hamsters: a model using intravitreal implantation of a peripheral nerve. $\mathcal{F}$ Neurocytol 1992; 21 :

12 Weibel D, Cadelli D, Schwab ME. Regeneration of lesioned rat optic nerve fibres is improved after neutralization of
myelin-associated growth inhibitors. Brain Res 1994; 642: 259-66.

13 So KF, Aguayo AJ. Lengthy regrowth of cut axons from ganglion cells after peripheral nerve transplantation into the retina of adult rats. Brain Res 1985; 328: 349-54. 
14 Thanos S, Mey J. Type-specific stabilization and targetdependent survival of regenerating ganglion cells in the retina of adult rats. $\mathcal{f}$ Neurosci 1995 ; 15: 1057-79.

15 Sauvé Y, Sawai H, Rasminsky M. Functional synaptic connections made by regenerated retinal ganglion cell axons in the superior colliculus of adult hamsters. $\mathcal{f}$ Neurosci 1995; 15: 665-75.

16 Thanos S. Adult retinofugal axons regenerating through peripheral nerve grafts can restore the light-induced pupilloconstriction reflex. Eur $\mathcal{F}$ Neurosci 1992; 4: 691-9.

17 Sperry RW. Visuomotor coordination in the newt (Triturus viridescens) after regeneration of the optic nerve. $\mathcal{F}$ Comp Neurol 1943; 79: 33-55.

18 Taylor JSH, Jack JL, Easter SS. Is the capacity for optic nerve regeneration related to continued retinal ganglion cell production in the frog? Eur $f$ Neurosci 1989; 1 : 626-38.

19 MacLaren RE, Taylor JSH. Myelination in the optic nerve of the opossum: correlations to a transient regenerative of the opossum: correlations to a transient regenerative
capacity of retinal ganglion cells. Soc Neurosci Abs 1994; 20: 467 .

20 MacLaren RE, Taylor JSH. A critical period for axon regrowth through a lesion in the developing mammalian retina. Eur $\mathcal{F}$ Neurosci 1995; 10: 2111-8.

21 Schreyer DJ, Jones EG. Growing corticospinal axons bypass lesions of neonatal rat spinal cord. Neuroscience 1983; 9: $31-40$.

22 Schnell L, Schwab ME. Sprouting and regeneration of lesioned corticospinal tract fibres in the adult rat spinal cord. Eur 7 Neurosci 1993; 5: 1156-71.

23 Reese BE, Colello RJ. Neurogenesis in the retinal ganglion cell layer of the rat. Neuroscience 1992; 46: 419-29.

24 Godement $P$, Salaün J, Imbert M. Prenatal and postnatal development of retinogeniculate and retinocollicular projections in the mouse. $\mathcal{F}$ Comp Neurol 1984; 230: 552-75.

25 Allodi S, Cavalcante L, Hokoç J, Bernardes R. Genesis of neurons in the retinal ganglion cell layer in the opossum. Anat Embryol 1992; 185: 489-99.

26 Taylor JSH, Guillery RW. Early development of the optic chiasm in the gray short-tailed opossum, Monodelphis domestica. F Comp Neurol 1994; 350: 109-21.

27 Saunders NR, Adam E, Reader M, Møllgård $K$ Monodelphis domestica (grey short-tailed opossum): an Monodelphis domestica (grey short-tailed opossum): an ment. Anat Embryol 1989; 180: 227-36.

28 de Beer GR. Development of the vertebrate skull. Oxford: Oxford University Press, 1937

29 Schnitzer J. Distribution and immunoreactivity of glia in the retina of the rabbit. $\mathcal{F}$ Comp Neurol 1985; 240: 128-42.

30 Distler C, Wiegel H, Hoffmann KP. Glia cells of the monkey retina. I. Astrocytes. F Comp Neurol 1993; 333: $134-47$.

31 Ling T, Mitrofanis J, Stone J. Origin of retinal astrocytes in the rat: evidence of migration from the optic nerve. the rat: evidence of migration from

32 Ling T, Stone J. The development of astrocytes in the cat retina: evidence of migration from the optic nerve. Dev Brain Res 1988; 44: 73-85.

33 Dreher Z, Wegner $M$, Stone J. Müller cell endfeet at the inner surface of the retina: light microscopy Vis Neurosci 1988; 1: 169-80.

34 Schnitzer J. Immunocytochemical studies on the development of astrocytes, Müller (glial) cells, and oligodendrocytes in the rabbit retina. Dev Brain Res 1988; 44: 59-72.

35 Holash JA, Stewart PA. The relationship of astrocyte-like cells to the vessels that contribute to the blood-ocular barcells to the vessels that contribute to
riers. Brain Res 1993; 629: 218-24.

36 Dusart I, Schwab ME. Secondary cell death and the inflammatory reaction after dorsal hemisection of the rat spina cord. Eur $¥$ Neurosci 1994; 6: 712-24.

37 Maxwell WL, Follows R, Ashhurst DE, Berry M. The response of the cerebral hemisphere to injury 1. The mature rat. Phil Trans $R$ Soc Lond B 1990; 328: 479-500.

38 Stone J, Dreher Z. Relationship between astrocytes, ganglion cells and vasculature of the retina. $\mathcal{f}$ Comp Neurol glion cells and vas

39 Price J, Turner D, Cepko C. Lineage analysis in the vertebrate nervous system by retro-virus-mediated gene transfer. Proc Natl Acad Sci USA 1987; 84: 156-60.
40 Robinson SR, Dreher Z. Müller cells in adult rabbit retinae; morphology, distribution and implications for function and development. F Comp Neurol 1990; 292: 178-92.

41 Schwab ME, Caroni P. Oligodendrocytes and CNS myelin are nonpermissive substrates for neurite growth and

2 MacLaren RE. Myelination in the opossum optic nerve: late appearance of inhibitors implicates an earlier non-myelin factor in preventing ganglion cell regeneration. $\mathcal{f}$ Comp factor in preventing gang
Neurol 1996 (in press).

43 Raff MC, Miller RH, Noble M. A glial progenitor cell that develops in vitro into an astrocyte or an oligodendrocyte depending on the culture medium. Nature 1983; 303: 390-6.

44 Small RK, Riddle P, Noble $M$. Evidence for migration of oligodendrocyte-type-2 astrocyte progenitor cells into the developing rat optic nerve. Nature 1987; 328: 155-7.

45 Berliner ML. Cytologic studies on the retina I. Normal coexistence of oligodendroglia and myelinated nerve coexistence of oligodendroglia and my

46 ffrench-Constant C, Miller RH, Burne JF, Raff MC. Evidence that migratory oligodendrocyte-type-2 astrocyte $(\mathrm{O}-2 \mathrm{~A})$ progenitor cells are kept out of the rat retina by a barrier at the eye-end of the optic nerve. $\mathcal{F}$ Neurocytol 1988; 17: 13-25.

47 Berry M, Hall S, Rees L, Carlile J, Wyse J. Regeneration of axons in the optic nerve of the adult Browman-Wyse (BW) mutant rat. $₹$ Neurocytol 1992; 21 : 426-48.

48 Trimmer PA, Wunderlich RE. Changes in astrological scar formation in rat optic nerve as a function of development. f Comp Neurol 1990; 296: 359-78.

49 Windle WF, Clemente CD, Chambers WW. Inhibition of formation of a glial barrier as a means of permitting a peripheral nerve to grow into the brain. $\mathcal{F}$ Comp Neurol 1952; 96: 359-69.

$50 \mathrm{Xu} \mathrm{XM}$, Martin GF. Developmental plasticity of the rubrospinal tract in the North American opossum. f Comp Neurol 1989; 279: 368-81.

51 Kalil K, Reh T. Regrowth of severed axons in the neonatal central nervous system: establishment of normal connections. Science 1979; 205: 1158-60.

52 Bregman BS. Spinal cord transplants permit the growth of serotonergic axons across the site of neonatal spinal cord serotonergic axons across the site of neonatal

53 Reier PJ, Bregman BS, Wujek JR. Intraspinal transplantation of embryonic spinal cord tissue in neonatal and adult rats. F Comp Neurol 1986; 247: 275-96.

54 Iwashita Y, Kawaguchi S, Murata M. Restoration of function by replacement of spinal cord segments in the rat. Nature 1994; 367: 167-70.

55 Smith GM, Rutishauser U, Silver J, Miller RH. Maturation of astrocytes in vitro alters the extent and molecular basis of neurite outgrowth. Dev Biol 1990; 138: 377-90.

56 Maxwell WL, Follows R, Ashhurst DE, Berry M. The response of the cerebral hemisphere to injury. II. The neoresponse of the cerebral hemisphere to injury. II. The neo-

57 Snow DM, Lemmon V, Carrino DA, Caplan AI, Silver J. Sulfated proteoglycans in astroglial barriers inhibit neurite outgrowth in vitro. Exp Neurol 1990; 109: 111-30.

58 Snow DM, Watanabe M, Letourneau PC, Silver J. A chondroitin sulfate proteoglycan may influence the direction of retinal ganglion cell outgrowth. Development 1991; 113: 1473-85.

59 Ghooray GT, Martin GF. Development of an astrocytic response to lesions of the spinal cord in the North American opossum: an immunohistochemical study using American opossum: an immunohistochemical study using

60 Sarthy PV, Fu M. Transcriptional activation of an intermediate filament gene in mice with retinal dystrophy. DNA 1989; 8: 437-46.

61 Eisenfield A, Bunt-Milam AH, Sarthy PV, Müller cell expression of glial fibrillary acidic protein after genetic and experimental photoreceptor degeneration in the rat retina. Invest Ophthalmol Vis Sci 1984; 25: 1231-328.

62 Scherer J, Schnitzer J. Intraorbital transection of the rabbit optic nerve: consequences for ganglion cells and neuroglia in the retina. F Comp Neurol 1991; 312: 175-92.

63 Erickson PA, Fisher SK, Guérin CJ, Anderson DH, Kaska DD. Glial fibrillary acidic protein increases in Müller cells after retinal detachment. Exp Eye Res 1987; 44: 37-48. 